\title{
Analyzing the profit-loss sharing contracts with Markov model
}

\author{
Imam Wahyudia,*, Ali Sakti ${ }^{\mathrm{b}}$ \\ ${ }^{a}$ Department of Management, Faculty of Economics and Business, Universitas Indonesia, Jl. Prof. Dr. Sumitro Djojohadikusumo, Kampus UI Depok 16424, \\ Indonesia \\ ${ }^{b}$ Bank Indonesia, Jl. MH. Thamrin 2 Jakarta 10350, Indonesia
}

Article history:

Received: 8 October 2016 / Received in revised form: 29 November 2016 / Accepted: 29 November 2016

\begin{abstract}
The purpose of this paper is to examine how to use first order Markov chain to build a reliable monitoring system for the profit-loss sharing based contracts (PLS) as the mode of financing contracts in Islamic bank with censored continuous-time observations. The paper adopts the longitudinal analy sis with the first order Markov chain framework. Laplace transform was used with homogenous continuous time assumption, from discretized generator matrix, to generate the transition matrix. Various metrics, i.e.: eigenvalue and eigenvector were used to test the first order Markov chain assumption. Cox semi parametric model was used also to analyze the momentum and wait ing time effect as non-Markov behavior. The result shows that first order Markov chain is powerful as a monitoring tool for Islamic banks. We find that waiting time negatively affected present rating downgrade (upgrade) significantly. Likewise, momentum covariate showed negative effect. Finally, the result confirms that different origin ratings have different movement behavior. The paper explores the potential of Markov chain framework as a risk management tool for Islamic banks. It provides valuable insight and integrative model for banks to manage their borrower accounts. This model can be developed to be a powerful early warning system to identify which borrower needs to be monitored intensively. Ultimately, this model could potentially increase the efficiency, productivity and competitiveness of Islamic banks in Indonesia. The analy sis used only rating data. Further study should be able to give additional information about the determinant factors of rating movement of the borrowers by incorporating various factors such as contract-related factors, bank-related factors, borrower-related factors and macroeconomic factors.
\end{abstract}

Keywords: profit-loss sharing, Islamic banking, default risk, Markov model, survivalrate.

\section{Introduction}

Even though murabahah dominates most of banking transactions, the portion of profit-loss sharing based (PLS) contracts, i.e. mudharabah and musharakah, is rising steadily, from 29.07\% in December 2005 to 31.29\% in December 2006 (see Fig. 1). It indicates two conditions: bank returns to serve the real sector and an increase of the bank's inherent risk. PLS contracts said to be able to promote economic growth, but they also have higher risk-return profiles [19]. In the salebased contract (murabahah, salam, istishna') or rent-based contract (ijarah), bank could claim the predetermined return through margin or fee/rental cost. In contrast, the return obtained from PLS contracts depends on the realization of the client's business profits. When the business suffered losses and capital is eroded, the bank can also be at risk of losing the fund given to the client. Thus, in PLS contract, banks also bear the rate of return risk and investment risk, in addition bear the default risk, as in murabahah, salam, istishna' and ijarah. Consequently, if the banks cannot maintain the competitive return to the depositors, they will face the displaced commercial risk and withdrawal risk [23, 25].

As the portion of financing in PLS contracts rises, financing risk (consist of default risk, the rate of return risk

* Corresponding author. Telp: +62 217272425 ; fax: +62 217863556 Email:i_wahyu@ui.ac.id and investment risk) will also increase. This increased risk should be responded positively by establishing a risk management system. Banks should have the reliable monitoring system to control risk. To build monitoring system, bank may implement a structural model, a scoring system or a reduced form model. By implementing the structural model or scoring system, banks could monitor the clients directly. However, in structural model, banks are required to know the market value of asset's client as well as their debts. Similarly, in scoring system, banks had to sacrifice time, effort and cost to collect relevant information about client and its business.

For an emerging market like Indonesia, majority clients in Islamic banks are personal or micro, small and medium enterprise (see Table 1). Their financing is relatively small in value, but large in number. This is often called as granularity [24]. In consequence, the cost to maintain clients and to gather related data is expensive [24]. In addition, the value of their assets is not available publicly. Thus, both model (structural model and scoring system) are difficult to perform. Alternatively, the bank may use the reduced form models. With a reduced model, bank may utilize available rating data to analyze clients' default behaviors, especially when the clients could be grouped perfectly based on its default categories. Rating data could be provided by independent rating agency, such as Fitch Rating, PEFINDO, Moody's, 
Standard \& Poor and ICRA, or by bank's rating system. However, the cost to maintain the rating system is expensive for banks. In the future, bank should turn over the appraisal and rating tasks to the external parties. So, the bank can focus on its core business, innovation in product, expanding to other segments, creating new markets, etc. Bank only needs to monitor the performance and quality of the client based on the rating given externally.

In this study, we implement the reduced form model, especially the JLT model [13]. With this model, we calculate the intensity of rating movement and the probability of default of the clients. Because the clients' financing tenor is relatively short-term, it causes none of the clients survive throughout the observation period. For this reason, we adjust the model by adding the 'right and left' sensor scheme. In addition, in the ratings data, we found that the default rating is not a perfect absorbing state, except when the client actually defaulted and were excluded from the rating system. Then, we examine deeper on the behavior of rating. Stability rating, as an indicator of the performance of risk management, is assessed using the transition rate and coefficient of variation. This study also tests whether the transition probabilities are constant or fluctuate over time. The assumption of first-order Markov chain is tested by Eigen analysis (Eigenvector and Eigenvalue) and metric measures (MSVD and MAGL). When the transition probability matrix is in-homogenous, we analyze whether the duration and the time covariate (momentum and waiting time) significantly affect the probability of default of individual clients.

The aim of this paper is to examine how to use first order Markov chain to build a reliable monitoring system for the profit-loss sharing based contracts (PLS) as the mode of financing contracts in Islamic bank with censored continuoustime observations.

\section{Literature Review}

\subsection{Debt Based vs. Profit Loss Sharing Based Contracts}

Naturally, PLS contracts, such as mudharabah and musharakah, have higher risk in compared with debt-based contracts such as salam, muajjal, istishna', ijarah and qardhul hasan. In mudharabah, Islamic banks release their fund to be managed solely by client. Banks are only allowed to obtain return based on the client's actual profit. When the client's business is in loss, banks must bear the loss based on bank's capital contribution. Banks are not permitted to request a predetermined return or guarantee for its capital. Banks could set some restrictions to secure their interests, but could not involve in client's business. Even in musharakah, Islamic banks practically only contribute in capital, not in management. Not only it is prohibited by regulation (Indonesia law No.21/2008), it also requires banks to provide large number of employee that are competent and skillful in client's business.

In PLS contracts, banks at least face two risks: investment risk and capital recovery risk. The client's realized-profits are fluctuation as well as the bank's return. The fluctuating return exposes bank to investment risk. Capital recovery risk arises when client is unable to repay the fund given by the bank. Both of these risks arise from two sides. First, the dynamics of economic environment may affect the client's financial performance as well as their ability to pay back the capital or to share profits. Second, moral hazard is very likely to arise due to asymmetric information between banks and clients [2]. Typically, banks will ask for rahn (collateral) and kafil (guarantor) to prevent capital loss. However, kafalah and rahn could only be useful in reducing the capital recovery risk that is caused by moral hazard effect, and not by business risk. Therefore, when client claimed to be experiencing financial distress, banks must be able to identify the factor: client's business risk or moral hazard. Moreover, failure in identifying client's default factors may cause the bank to lose its entire fund.

\subsection{Financing Portfolio in Indonesian Islamic banking}

There has been an increase in portion of Islamic financing based on the PLS from $29.07 \%$ on January 2005 to $31.29 \%$ on December 2006 (see Fig. 1). Despite relatively insignificant, this increase showed positive direction toward the true form of Islamic banking. Usually, Islamic banks in its early developments favor murabahah as financing mode rather than PLS. Quasi-fixed income and debt form of murabahah are some contributing factors to this preference. PLS tend to have greater risks than murabahah. The lack of available competent human resources, the absence of business skills and high potentials of moral hazards are the inhibiting factors for Islamic banks' intention to use PLS as their financing mode. Mills and Presley [19] stated that PLS contracts are the contracts associated with higher risk-return profiles. It is why this contract required amanah (trustworthiness) and mutual trust between bank and client [7,25].

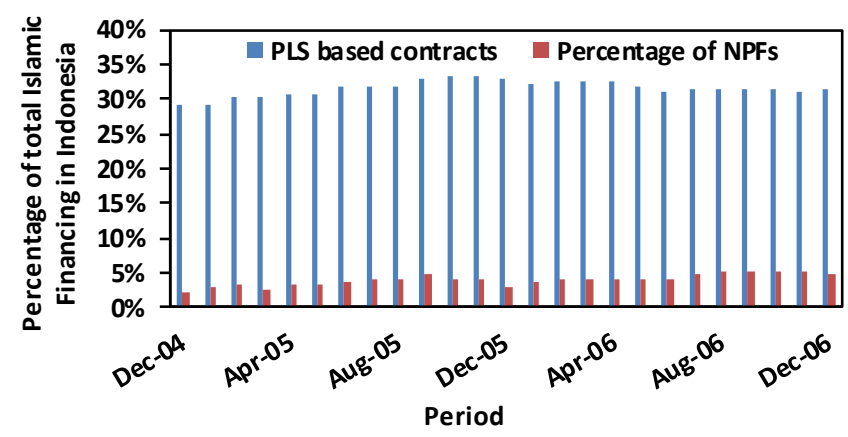

Fig. 1. Patterns of PLS and NPFs in Indonesian Islamic banking

In general, the default risk of PLS in Indonesia is relatively small. Most PLS contracts have rating current (L) $(96.00 \%)$. Meanwhile, the rest have varied ratings, rating special mention (DPK) $(0.15 \%)$, rating substandard (KL) (1.44\%), rating doubtful (D) $(0.78 \%$ ), and rating loss (M) (1.63\%) during the period of December 2005 - December 2006. However, Fig. 1 indicates that the increase in PLS financing portion to the total financing is followed by the increase of NPF (non performing financing).

\subsection{Markov Model: Discrete and Continuous Approach}

Following Janssen and Manca [12], a sequence of random variables, $J_{n}, n \in N$, is said to be a Markov chain if for every $j_{0}, j_{1}, \ldots, j_{n} \in J$, if $P\left(J_{n}=j_{n} \mid J_{0}=j_{0}, j_{1}=j_{1}, \ldots, j_{n-1}=j_{n-1}\right)=P\left(J_{n}\right.$ $\left.=j_{n} \mid j_{n-1}=j_{n-1}\right)$. As a Markov chain, $J_{n}, n \in N$, is homogeneous if the probability of an event is independent on time $n$ and be 
said inhomogeneous if others. For the homogeneous case, the probability of the occurrence that $J=i$ in time $n$, when in time $n-1, J=j$ occurred can be written as:

$$
P\left(J_{n}=i \mid J_{n-1}=j\right)=p_{i, j}
$$

Then a transition probability matrix can be defined as :

$$
\boldsymbol{P}=\left[\begin{array}{ccccc}
p_{1,1} & p_{1,2} & \ldots & p_{1, n-1} & p_{1, n} \\
p_{2,1} & p_{2,2} & \ldots & p_{1, n-1} & p_{2, n} \\
& \vdots & \ddots & & \vdots \\
p_{m-1,1} & p_{m-1,2} & \ldots & p_{m-1, n-1} & p_{m-1, n} \\
p_{m, 1} & p_{m, 2} & & p_{m, n-1} & p_{m, n}
\end{array}\right]
$$

In case the model has an absorbing state, e.g. (default) risk case, we can write it as:

$$
\boldsymbol{P}=\left[\begin{array}{ccccc}
p_{1,1} & p_{1,2} & \ldots & p_{1, n-1} & p_{1, n} \\
p_{2,1} & p_{2,2} & \ldots & p_{1, n-1} & p_{2, n} \\
& \vdots & \ddots & \vdots & \\
p_{m-1,1} & p_{m-1,2} & \ldots & p_{m-1, n-1} & p_{m-1, n} \\
0 & 0 & & 0 & 1
\end{array}\right]
$$

Where every element of the $\mathbf{P}$ matrix has the following characteristics:

1. $p_{i j} \geq 0$ for every $i, j \in I$

2. $\sum_{j \in I} p_{i j}=1$ for every $i, i \in I$.

In order to explain the evolution of Markov chain perfectly, we need to adjust the original distribution for condition $J_{0}$, i.e. vector $p=\left(p_{1}, \ldots, p_{m}\right)$ that fulfill $\sum_{i \epsilon I} p_{i}=1$, where $p_{i} \geq 0$ and $i \in I$. So for every $i, p_{i}$ represent the original probability on condition $i$, i.e. $p_{i}=P\left(J_{0}=i\right)$. In this definition, it can be shown that the transition probability of order $p_{i j}^{(n)}$ can be defined as:

$$
p_{i j}^{(n)}=P\left(J_{v+n}=j \mid J_{v}=i\right)
$$

For $n=2$, we get the result as:

$$
p_{i j}^{(2)}=\sum_{k} p_{i k} \cdot p_{k j}
$$

\subsubsection{Discrete-time approach}

Consider a sample of $N$ objects (i.e. firms, clients, etc.) whose transitions between different states are observed at discrete times $t=0,1, \ldots, T$ (i.e. daily, monthly, quarterly, semi-annually, annually, etc.). Let $n_{i}(t)$ be the number of objects in state $i$ at date $t, n_{i j}(t)$ is the number of objects which went from rating $i$ at time $t-1$ to rating $j$ at time $t$, where $N_{i}(T)=\sum_{t=0}^{T-1} n_{i}(t)$ is the total number of objects recorded at the beginnings of the transition periods, and $N_{i j}(T)=$ $\sum_{t=1}^{T} n_{i j}(t)$ is the total number of transitions observed from rating $i$ to rating $j$ over the entire period $(\mathrm{T})$.

The probability of observing a particular path $x_{0}, x_{1}, \ldots, x_{T}$ of one object is $p_{x_{0}, x_{1}}, p_{x_{1}, x_{2}}, \ldots, p_{x_{T-1}, x_{T}}$. In independent condition, we get products of the individual likelihoods and hence the complete likelihood function takes the following form:

$$
\prod_{(i, j)} p_{i j}^{N_{i j}(T)}
$$

where $p_{i j}^{0}=1$. Therefore, the log-likelihood is:

$$
\prod_{(i, j)} N_{i j}(T) \cdot \log \left(p_{i j}\right)
$$

Maximizing the formula with restriction $\sum_{j=1}^{K} p_{i j}=1$ for every $i$ using a standard Lagrange multiplier, we can solve the formula to obtain:

$$
\hat{p}_{i j}=\frac{N_{i j}(T)}{N_{i}(T)}
$$

From the last equation above, it can be concluded that any rating changes that occurs within the period was not counted. The other name of this approach is cohort approach and widely used in (banking and financial) industry [11].

\subsubsection{Continuous-time with time-homogeneous approach}

Originally developed and applied in biology and medicine literatures, this model is categorized under the heading of survival analysis. Principally, this model is similar with the cohort approach that turns in continuous form with Laplace transformation (i.e. exponential distribution assumption). There are two advantages of this model, i.e. (i) it can count any rating change that occurs within the observation period, and (ii) it can accommodate (right) censoring and (left) truncating in financing contract rating history [11]. Meanwhile, the cohort approach ignores both of these is sues. There are also several other advantages of the continuous time method [17], which are:

1. The framework permits a rigorous formulation and testing of 'rating drift' assumptions and other type of non-Markov behavior (such as seasonal effects).

2. The dependence on external covariates and changes in 'regimes' due to business cycles can be formulated and tested.

3. The continuous-time formulation hooks up nicely with rating-based term structure modeling in which one tries to estimate and calibrate yield curves for different rating classes.

4. When estimating homogeneous chains in continuoustime by estimating the generator of the continuous-time Markov chain, we could avoid the 'embedding problem' for Markov chains. This problem arises because not every discrete time Markov chain can be realized as a discretized continuous-time chain.

Let $\Lambda$ be a $N \times N$ generator (or intensity) matrix. Following Lando and Skodeberg [17], we defined the $N \times N$ transition probability matrix $\boldsymbol{P}(t)$ as:

$$
P(t)=\exp (\Lambda t), \quad t \geq 0
$$

Where $\exp ($.$) is a matrix exponential operation, and \Lambda$ satisfy these conditions:

$$
\begin{gathered}
\lambda_{i j} \geq 0 \quad \text { for } i \neq j \\
\lambda_{i i}=-\sum_{j \neq i} \lambda_{i j}
\end{gathered}
$$

The second expression merely states that the diagonal elements used are such to ensure that the rows sum up to zero. In matrix form, $\Lambda$ can be written as:

$$
\boldsymbol{\Lambda}=\left[\begin{array}{ccccc}
\lambda_{1,1} & \lambda_{1,2} & \ldots & \lambda_{1, N-1} & \lambda_{1, N} \\
\lambda_{2,1} & \lambda_{2,2} & & \lambda_{2, N-1} & \lambda_{2, N} \\
& \vdots & \ddots & \vdots & \\
\lambda_{N-1,1} & \lambda_{N-1,2} & \ldots & \lambda_{N-1, N-1} & \lambda_{N-1, N} \\
\lambda_{N, 1} & \lambda_{N, 2} & & \lambda_{N, N-1} & \lambda_{N, N}
\end{array}\right]
$$

In an absorbing state case, all elements in the last row are predetermined zero. The diagonal elements can be defined immediately after the non-diagonal element is obtained. Obtaining estimates of the elements of $\Lambda$ by following maximum likelihood estimator (MLE):

$$
\hat{\lambda}_{i i}=\frac{N_{i j}(T)}{\int_{0}^{T} Y_{i}(s) d s}
$$

Where $Y_{i}(s)$ is the number of the objects in rating $i$ at time $\mathrm{s}$ and $N_{i j}(T)$ is the total number of transitions over the period 
from rating $i$ to rating $j$, where $\mathrm{i} \neq \mathrm{j}$. Furthermore, the numerator counts the number of observed transitions from rating $i$ to rating $j$ over the entire period of observation. The denominator has the number of 'firm-years' spent in state $i$.

The mathematical derivation of Markov process with continuous and homogeneous time can be seen in the Appendix.

\subsubsection{Continuous-time with time-inhomogeneous approach}

This model uses a non-parametric method and allows for non-homogeneity while fully accounting for all rating movements within the observation periods. For the transition probabilities $\mathbf{P}(s, t)$, given that our sample has $m$ transitions over period from $s$ to $t$, we can estimate them with AalenJohansen estimator or product-limit estimator [1]:

$$
\widehat{\boldsymbol{P}}(s, t)=\prod_{i=1}^{m}\left(I+\Delta \widehat{\boldsymbol{A}}\left(T_{i}\right)\right)
$$

Where $T_{i}$ is a jump time in the interval $[\mathrm{s}, \mathrm{t}]$ and

$$
\Delta \widehat{\boldsymbol{A}}\left(T_{i}\right)=\left[\begin{array}{ccccc}
-\frac{\Delta N_{1,1}\left(T_{i}\right)}{Y_{1}\left(T_{i}\right)} & \frac{\Delta N_{1,2}\left(T_{i}\right)}{Y_{1}\left(T_{i}\right)} & \cdots & \frac{\Delta N_{1, p-1}\left(T_{i}\right)}{Y_{1}\left(T_{i}\right)} & \frac{\Delta N_{1, p}\left(T_{i}\right)}{Y_{1}\left(T_{i}\right)} \\
\frac{\Delta N_{2,1}\left(T_{i}\right)}{Y_{2}\left(T_{i}\right)} & -\frac{\Delta N_{2,2}\left(T_{i}\right)}{Y_{2}\left(T_{i}\right)} & \cdots & \frac{\Delta N_{2, p-1}\left(T_{i}\right)}{Y_{2}\left(T_{i}\right)} & \frac{\Delta N_{2, p}\left(T_{i}\right)}{Y_{2}\left(T_{i}\right)} \\
\frac{\Delta N_{p-1,1}\left(T_{i}\right)}{Y_{p-1}\left(T_{i}\right)} & \frac{\Delta N_{p-1,2}\left(T_{i}\right)}{Y_{p-1}\left(T_{i}\right)} & \ddots & -\frac{\Delta N_{p-1, p-1}\left(T_{i}\right)}{Y_{p-1}\left(T_{i}\right)} & \frac{\Delta N_{p-i, p}\left(T_{i}\right)}{Y_{p-1}\left(T_{i}\right)} \\
\frac{\Delta N_{p, 1}\left(T_{i}\right)}{Y_{p}\left(T_{i}\right)} & \frac{\Delta N_{p, 2}\left(T_{i}\right)}{Y_{p}\left(T_{i}\right)} & \cdots & \frac{\Delta N_{p, p-1}\left(T_{i}\right)}{Y_{p}\left(T_{i}\right)} & -\frac{\Delta N_{p, p}\left(T_{i}\right)}{Y_{p}\left(T_{i}\right)}
\end{array}\right]
$$

Where $\Delta N_{h j}\left(T_{i}\right)$ denotes the number of transitions observed from rating $h$ to rating $j$ at time $T_{i}$, and $Y_{k}\left(T_{i}\right)$ is the number of firms in rating $k$ right before time $T_{i}$. Therefore, this estimator can be seen as a cohort method applied to extremely short time intervals. All elements in the last row are predetermined zero in absorbing state case.

\section{Data and Methodology}

\subsection{Data}

The data sample used in this study covered 17,184 PLS contracts in Indonesian Islamic banking industry within monthly period, January 2004 - September 2005. Rating data is gathered from two types of Islamic banks, i.e. Islamic commercial bank and Islamic banking unit. Indonesia still has Islamic banking unit because, based on "Law No. 21/2002", Indonesia still employs dual banking system that allows conventional banks to open Islamic banking service (office channeling) or also called Islamic bank unit. Rating system adopted in Indonesia consists of 5 rating, i.e. L (current), DPK (special mention), KL (substandard), D (doubtful) and $\mathrm{M}$ (loss). These rating are measured from any quantitative measure as well as qualitative information.

\subsection{Models and Methods}

\subsubsection{Estimating the transition probability matrix}

This paper shows how to use Markov model framework in order to explain the risk profile of the clients and their behavior over time. From the database, we confirm that data do not fully satisfied survival data conditions because there were many clients that entered bank's rating system after observation period was started (left censoring) or left the system before the period is ended (rating withdrawal or right censoring). Additional class of rating is used to accommodate the left/right censoring, i.e. NR (not rated) $[8,11,17,18]$. Out of 17.184 clients, nearly all of them have at least one "NR" case.

Bangia et al. [8] explained that, theoretically, the transition matrix could be estimated for any desired transition horizon. The shorter the measurement interval, the fewer rating changes are omitted. Based on this consideration, quarterly time horizon is used in this research. One additional reas on is that quarterly data is considered adequate (i.e. not too long nor too short) for adopting various changes of risk management policy by both the regulator and the bank's management. With $t$ defined as quarterly, we get seven cohort transition matrixes for January 2004 - September 2005 monthly period using equation 8 . Non-weighted average approach was used to obtain the transition probability matrix for the next quarter:

$$
\widehat{\boldsymbol{P}}_{i j}(\Delta t=1 \text { quarter })=\frac{\sum_{t=1}^{T} \widehat{\boldsymbol{P}}_{i j}(t)}{T}
$$

Where $\mathbf{P}_{\mathrm{ij}}(\mathrm{t})$ is the transition probability matrix for the $t$ quarter.

After estimating $\mathbf{P}$, we should discard the NR class rating from the matrix since it is meaningless in the context of industry and risk management. For the hazard model, Lando and Skodeberg [17] suggest modification in the generator matrix to omit NR with estimation under censor mechanism. Kavvathas [18] explained the mechanism for adjusting the generator matrix in detail. He uses denominator correction that was suggested by Klabfleisch and Prentice [14] and used by Moody's, i.e. with appropriate rescaling so that sum of raw in $\mathbf{P}$ is one (i.e. $\sum_{j \neq N R} p_{i j}=1$ ). Kavvathas [18] explained that Moody's estimator uses life table estimator of constrained probability of default in relevant interval correction as basis for sensor mechanism. This sensor is related with the withdrawn rating (NR) during the relevant period of time. One can estimate the constrained probability of default of $p_{j}$ within the interval $I_{j}$, where $m_{j}$ is the number of censored observation, $d_{j}$ is the number of default and $n_{j}$ is the number of observation at risk within one time before $t_{j}$, as: $\hat{p}_{j}=$ $d_{j} /\left[n_{j}-\frac{m_{j}}{2}\right]$. Correction in this denominator is an attempt to capture the reality that the individual firm at risk might not be at risk during the entire interval.

Jarrow et al. [13] provided an adjustment alternative to the transition probability matrix (not the generator matrix) to eliminate "NR", which is done by rescaling the number of line in the transition probability to return to one, i.e. $\sum_{j \neq N R} p_{i j}=$ 1. Jarrow et al. [13] explained that eliminating the portion of NR from the sample is by redefining the transition probability from $\mathrm{i}$ rating to $\mathrm{j}$ rating (except $\mathrm{NR}$ ) as:

$\hat{p}_{i j}=\frac{\text { fraction of the firms that migrated from state } i \text { to } j}{\text { total fraction of the firms that migrated from state } i \text { to any state } j(\text { except NR) }}$.

Bangia et al. [8] explained that there are three methods to eliminate NR. The first method treats transitions to NR as unfavorable information regarding the change in credit quality of the client. Probability of transiting to NR is distributed among downgraded and defaulted states in proportion to their values by allocating NR values to all cells to the right of diagonal. The second method treats transitions to NR status as favorable. The probability transitions to NR are distributed among all states, except default, in proportion to their values. 
This is achieved by allocating the probability of transiting to NR to all but not to the default column. The third method, which has emerged as an industry standard, treats transitions to NR status as non-information. The probability of transitions to NR is distributed among all states in proportion to their values. This is achieved by gradually eliminating firms whose ratings are withdrawn. We also use this method, which appears sensible and allows for easy comparisons to other studies $[11,13,17]$.

There are at least 3 approaches to solve the exponential matrix for equation 9:

$$
\begin{aligned}
& \text { 1. } \exp (\boldsymbol{\Lambda} t)=\sum_{n=0}^{\infty} \boldsymbol{\Lambda}^{n} \frac{t}{n !} \\
& \text { 2. } \exp (\boldsymbol{\Lambda} t)=\lim _{n \rightarrow \infty}\left(\boldsymbol{I}+\boldsymbol{\Lambda} \frac{t}{n}\right)^{n} \\
& \text { 3. } \exp (\boldsymbol{\Lambda} t) \approx\left(\boldsymbol{I}-\boldsymbol{\Lambda} \frac{t}{n}\right)^{-n}=\left[\left(\boldsymbol{I}-\boldsymbol{\Lambda} \frac{t}{n}\right)^{-1}\right]^{n}
\end{aligned}
$$

This research uses the first approach, which was also used by Jarrow et al. [13], Bangia et al. [8], Kavvathas [18], Lando and Skodeberg [17], Jafry and Schuermann [11], and others.

By using the decomposition approach, we can obtain the transition probability matrix for next year from the quarterly basis. The probability of default from this matrix can be used as input for calculating additional minimum capital requirement as required by Basel II. For example $p_{i j}(t)$ is the probability of transition from the initial state of $i$ to the new state of $j$ on the discrete time of $t$, where as $t=1,2, \ldots, T$. Then the probability of $p_{i j}$ during the period of $[0, T]$ can be defined as:

$$
\boldsymbol{P}_{i j}(\mathrm{~T})=\prod_{t=1}^{T} \boldsymbol{P}_{i j}(\mathrm{t})
$$

\subsubsection{Testing the non-Markov properties}

Using notation by Jafry and Schuermann [11], if $\mathrm{P}$ is time homogenous, while $\Lambda$ is a diagonal matrix with eigenvalue $P$, and $\mathrm{S}$ is matrix with related eigenvector, thus $\mathrm{P}$ can be stated in form of eigenvalue decomposition as follows:

$$
\mathbf{P}=\mathbf{S} \boldsymbol{\Lambda} \mathbf{S}^{-1} \text { and } \mathbf{x}(\mathrm{k})=\mathbf{x}(0) \mathbf{S} \boldsymbol{\Lambda}^{\mathrm{k}} \mathbf{S}^{-1}
$$

Where $\mathbf{x}(\mathrm{k})$ is the $\mathrm{k}$ time state vector in the future. For cases in which the number of row in the transition probability matrix equals to one, in the long run it is neutrally stable. This implies that at least one eigenvalue have a value of one and the rest have values decaying in the rate of increase in $k$-th power [11]. Steady state equilibrium is reached if $\mathbf{P}^{\mathrm{k}}=\mathbf{P}^{\mathrm{k}+1}$ requirement is satisfied [26].

Bangia et al. [8] explained further that transition probability matrix follows first order Markov chain process if both following conditions are satisfied. The first condition is that the eigenvalues of transition matrices for increasing time horizons needs to decay exponentially. While the second condition is that the set of eigenvectors for each transition matrix needs to be identical for all transition horizons.

Arvanitis et al. [6] offered another solution for testing the first order Markov assumption using a certain measurement (metric), which is $\Delta \mathrm{M}_{\mathrm{AGL}}$. This metric is used to test the basic assumption that the eigenvector of transition matrices are constant all the time. The procedure is as follows: (1) calculate the monthly generator matrix $\Lambda(t)$ and (2) calculate the metric value:

$$
\Delta M_{A G L}\left[\boldsymbol{\Lambda}(t), \Lambda^{\prime}(t)\right]=\frac{\left\|\boldsymbol{\Lambda}(t) \Lambda^{\prime}(t)-\Lambda^{\prime}(t) \Lambda(t)\right\|}{\|\boldsymbol{\Lambda}(t)\| \times\left\|\Lambda^{\prime}(t)\right\|}
$$

Where $\boldsymbol{\Lambda}(t)$ is the generator matrix calculated monthly and quarterly, while $\boldsymbol{\Lambda}^{\prime}(t)$ is the quarterly unweighted average generator matrix estimated during the period of January 2005December 2006.

The value of the metric, which falls between zero and two, equals zero if $\boldsymbol{\Lambda}(t)$ and $\boldsymbol{\Lambda}^{\prime}(t)$ have equal eigenvectors (without considering the eigenvalues) and increases along with the difference between both eigenvectors increases [11]. Rather than the generator matrix $\Lambda(t)$, Jafry and Schuermann [11] chose to use transition probability matrix, $\mathbf{P}(\mathrm{t})$, to define metric $\Delta M_{A G L}(\mathbf{P}, \widehat{\mathbf{P}})$. They also proposed a metric based on the average of singular values in the mobility matrix, which is:

$$
M_{S V D}[\mathbf{P}] \cong \frac{\sum_{n=1}^{N} \sqrt{\lambda_{n}\left(\mathbf{P}^{\prime} \mathbf{P}\right)}}{N}
$$

In defining the MSVD metric, Jafry dan Schuermann [11] used the square root of average eigenvalue from $\left[\mathbf{P}^{\prime} \mathbf{P}\right]$ rather than the largest eigenvalue. Since the total values for each row in the transition probability matrix equals to one (single stochastic process), the largest eigenvalue usually is one. Thus using the square root of the largest eigenvalue became less useful on many conditions.

\section{Results and Discussion}

\subsection{Rating Migration: Discrete vs. Continuous Time}

After eliminating NR, we obtained quarterly cohort matrices over period of January 2005 - September 2006 as shown in Table 1. All diagonal elements show probability to stay on its initial rating $i$. Value in diagonal elements refers to the stability level of transition probability matrix [10,21]. Two most stable ratings are the extreme rating on opposite side, which is $\mathrm{L}(96.95 \%)$ and $\mathrm{M}(34.87 \%)$. While the three middle ratings, which are DPK (14.79\%), KL (8.30\%) and D $(4.55 \%)$, have greater tendency to move out from its initial rating. Migration to the right shows a rating downgrade, which means the default risk becomes greater than before. On the other hand, migration to the left shows a rating upgrade and an improvement of the client rating's quality. Nearly all rating tends move to the left, towards $\mathrm{L}$ (upgrade). Table 1 shows that worse ratings have a higher probability to migrate to the right (downgrade). Furthermore, Trueck and Rachev [22] suggested various measures for comparing transition matrices from a Value-at-Risk perspective regarding matrix stability issue and direction of rating movement.

Table 1 presents the weakness of cohort approach. In

\begin{tabular}{|c|c|c|c|c|c|c|}
\hline & \multicolumn{5}{|c|}{ Destination Rating $(j, t+1)$} & \multirow{2}{*}{ Sum } \\
\hline & $\mathbf{L}$ & DPK & $\mathbf{K L}$ & D & $\mathbf{M}$ & \\
\hline \multirow{5}{*}{ 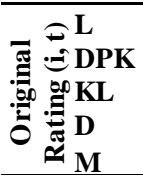 } & 0.96947 & 0.00129 & 0.01029 & 0.00756 & 0.01140 & 1.00000 \\
\hline & 0.54063 & 0.14792 & 0.17813 & 0.00833 & 0.00000 & 1.00000 \\
\hline & 0.85527 & 0.00124 & 0.08299 & 0.03113 & 0.02937 & 1.00000 \\
\hline & 0.78048 & 0.00000 & 0.00245 & 0.04552 & 0.17154 & 1.00000 \\
\hline & 0.63862 & 0.00000 & 0.00961 & 0.00308 & 0.34869 & 1.00000 \\
\hline
\end{tabular}
cohort, the probability of transition from DPK to $\mathrm{M}$ is equal to zero. Upward movements from rating $\mathrm{M}$ or D to DPK also have similar case. Cohort approach is incapable to capture issues of gradual movement that might transpire between discrete time points [17].

Table 1. Transition matrix with cohort approach

In contrast with the cohort approach, the hazard rate model 
calculates various rating transition between discrete time points. The model is able to capture probabilities of gradual movement. Estimation result of the generator matrix that shows the average rate of migration (i.e. instantaneous transition rate) during the observation period is shown in Table 2. The sum of each row is zero to satisfy the conditions of Laplace transformation with exponentially distribution assumption in transition activity [3,13]. Using Ross [20] method, we can obtain transition probability matrix for the next quarter as shown in Table 3.

Table 2 shows that all non-diagonal elements of the generator matrix have positive value. Positive sign showed rating movement process, while negative sign on diagonal elements were used to absorb the entire rating movement occurrences. Diagonal elements equal to zero indicates that no clients experienced rating transition. In other words, at the end of the next quarter, all clients remained at their current rating. Basically, a generator matrix tries to capture rating transition in discrete time with shorter interval than cohort. So, if cohort model was estimated on similar interval time period with generator matrix, both should have indifferent degree of capability in capturing gradual movements. These gradual migrations would be captured when continuing matrix generator. Laplace transformation is used to avoid 'embedding problem' of Markov chains. This problem arises because not every discrete time Markov chain can be realized as a discretized continuous-time chain [17].

Table 2. Instantaneous transition matrix

\begin{tabular}{|c|c|c|c|c|c|c|c|c|}
\hline & \multicolumn{6}{|c|}{ Destination Rating $(\mathrm{j}, \mathrm{t}+\mathbf{1})$} & \multirow[b]{2}{*}{ Sum } \\
\hline & & NR & $\mathbf{L}$ & DPK & KL & D & M & \\
\hline \multirow{6}{*}{ 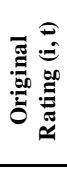 } & NR & -0.20764 & 0.19921 & 0.0 & 0.00273 & 0.00201 & 0361 & 0.00000 \\
\hline & & & & & & & & \\
\hline & DPK & 0.1 & & -2.0 & 0.2 & 0.0 & 99 & \\
\hline & KL & 0.2 & & 0.0 & -2 . & 0.0 & 21 & 00 \\
\hline & & 0.24153 & 1.35699 & 0.00 & 0.06992 & -1.87182 & 0.20021 & 0.00000 \\
\hline & M & 0.35807 & 1.02861 & 0.00000 & 0.06437 & 0.02816 & -1.47921 & 0.00000 \\
\hline
\end{tabular}

Table 2 provides information regarding client's rating movement behaviors. If at present there are 1,000 clients with rating $L$, then at the end of the next quarter there will be (i) as many as 261 clients with financing contract that will be finished; and (ii) 50 clients with downgraded rating, which consist of 3 clients to DPK; 26 clients to KL; 7 clients to D; and 14 clients to M. Moreover, if at present there are 1,000 clients with rating $\mathrm{M}$, then: (i) 358 clients would be excluded from banking rating system due to finished financing contract or terminated due to default; and (ii) 1,121 clients would experience rating upgrade, in which 1,029 would be upgraded to $\mathrm{L}$ where some clients upgraded more than once in the period); 64 clients upgraded to KL and 28 clients upgraded to D.

Table 2 should be interpreted differently from Table 1, in which Table 1 refers to the probability of client to remain in their current rating, the probability to move upward (downward) or to exit the rating system. On the other hand, Table 2 refers to the level of client group based on their rating category. However, both tables refer to the same general behavior of all clients at their present rating group.

Table 3 shows the behavior of clients' rating transition in Indonesian Islamic banking. It also shows that Indonesian Islamic banking tends to become better in financing contract quality. The probability of upward migration to rating $\mathrm{L}$ is greater than $66.15 \%$ for all other ratings. Even clients from rating $\mathrm{D}$ and $\mathrm{M}$ have tendency for upgrade to $\mathrm{L}$ than staying in their initial rating. In the hazard model, with monthly interval, the generator matrix is capable of capturing gradual movements during quarterly interval. For example, if client A in January 2005 has rating KL, in February 2005 it upgrades to rating DPK, and in March 2005 falls again into worst rating M. The cohort model would only capture movement of client A from KL to M so the transition probability from DPK to M is zero (i.e. omitted). But in the hazard model, two movements can be counted in the model so there would always be nonzero probability in transition from DPK to $M$. Thus, the hazard model is preferred to cohort model to assess the financing risk $[11,17,18]$.

Table 3. Transition matrix with time continuous approach

\begin{tabular}{|c|c|c|c|c|c|c|}
\hline & \multicolumn{5}{|c|}{ Destination Rating $(j, t+1)$} & \multirow{2}{*}{ Sum } \\
\hline & $\overline{\mathbf{L}}$ & DPK & KL & D & $\mathbf{M}$ & \\
\hline \multirow{5}{*}{ 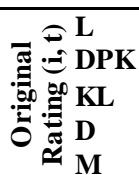 } & 0.97443 & 0.00125 & 0.01181 & 0.00392 & 0.00859 & 1.00000 \\
\hline & 0.77688 & 0.16076 & 0.04412 & 0.00921 & 0.00902 & 1.00000 \\
\hline & 0.80790 & 0.0 & 0. & 1305 & 1649 & 1.00000 \\
\hline & 0.72948 & 0.00 & 0.01999 & 0.19675 & 0.05249 & 1.00000 \\
\hline & 0.66148 & 0.00065 & 0.02052 & 0.00945 & 0.30789 & 1.00000 \\
\hline
\end{tabular}

Bangia et al. [8] found that probability transition matrices exhibit higher default risk and higher migration volatility for rating with lower quality. Table 3 show that default likelihood increases exponentially with decreasing rating. Unlike Bangia et al. [8], however, no such monotonistic property is found in Table 3. On the contrary, Table 3 shows properties of matrix instability in which the probability of staying at initial rating is lower than $31.00 \%$ for all rating (except L). Further, Figure 2 shows the coefficient of variation that is used to measure instability of each matrix elements. Moreover, volatility of movements between rating $\mathrm{DPK}, \mathrm{KL}$ and $\mathrm{D}$ is relatively higher than rating $\mathrm{L}$ and $\mathrm{M}$.

Based on information shown in Table 3, Islamic banking in Indonesia should give special attention and tighter supervisory mechanis $m$ toward clients who downgraded from rating $\mathrm{L}$. Even though their potential to recover to rating $\mathrm{L}$ is substantial (more than $66.15 \%$ ), there are $33.85 \%$ probability to move to rating $\mathrm{DPK}, \mathrm{KL}$ and $\mathrm{D}$. This probability is significant considering the amount of capital that must be set aside as reserve due to increasing NPF.

Moreover, these clients who have difficulties to return to rating $\mathrm{L}$ may be the clients with huge and significant exposure in the bank's financing portfolio. If Is lamic banking is willing to correct and improve their current supervisory mechanism, there may be possibility that in the next 5 to 10 years, the structure of this transition probability matrix would be improved.

Fig. 2 also indicates that the supervisory mechanism in Indonesian Islamic banks is still responsive and not proactive. Early warning systems are still incapable to correctly predict which clients in the rating $\mathrm{L}$ that will experience rating downgrade in the next quarter. The coefficient of variation for rating DPK, KL and D indicates that: (i) the current rating assessment for bank's clients, especially clients in rating $\mathrm{DPK}, \mathrm{KL}$ and $\mathrm{D}$, is imprecise or (ii) Islamic banks assigned them to rating L prematurely. Either way, this shows that risk mitigation system in Indonesian Islamic banking have not functioned properly. 


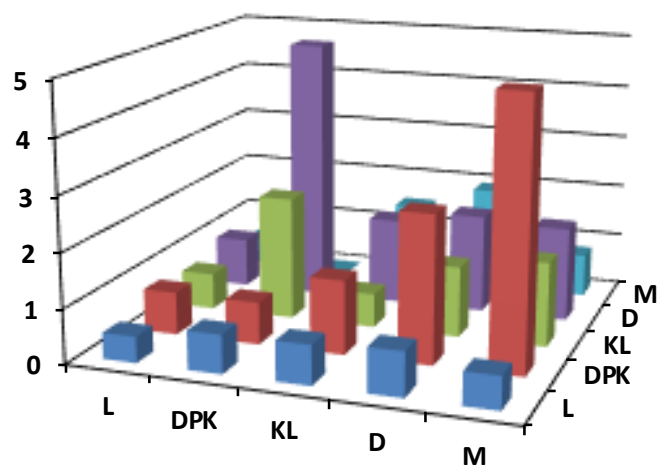

Fig. 2. Coefficient of variation

\subsection{Non-Markov Behavior Analysis}

\subsubsection{Eigenvalue and eigenvector analysis}

Eigenvalue and eigenvector were analyzed in order to test the homogenous time assumption. If the eigenvalue of the transition matrix were exponentially decreasing while the eigenvector were constant along the time horizon, then the assumption that the transition matrix follows first order Markov process is valid. This implies that the rating transitions are only influenced by current rating and not by other factors such as the momentum from previous transition or the length of time at the current rating. Fig. 3 indicates that the second, third, fourth, and fifth eigenvalues of transition matrices decays exponentially with longer transition horizons varying from one quarter to four years.

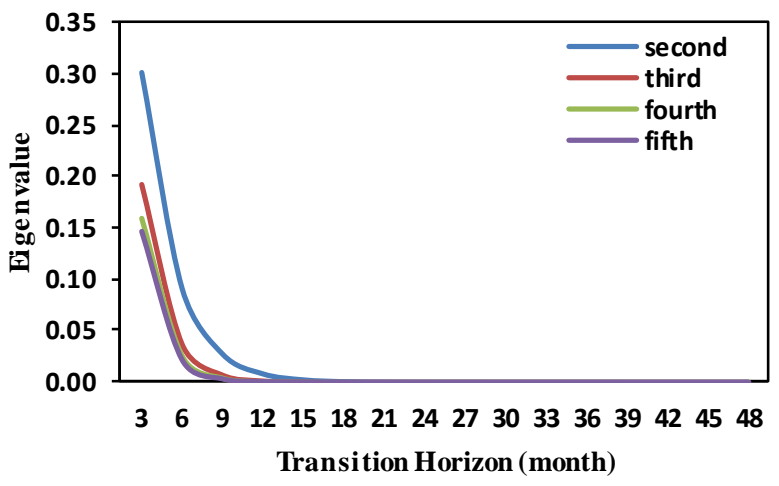

Fig. 3. Eigenvalue analysis

Fig. 3 confirms that the first order Markov process property is present in the transition probability matrix. The second property related to the eigenvector structure of the transition matrix shows the dynamics of rating transition. It shows the (asymptotic) distribution of surviving clients (not absorbed in the absorbing rating, if any) and their direction of convergence. Fig. 4 shows that the similar property of eigenvector value is not clearly found in every time horizon. However, we find patterns that after 3 years, eigenvectors converged at a certain value as indication of reaching the steady state equilibrium. Based on the findings in Fig. 3 and 4, the hypothesis on the presence of the first order Markov process property cannot be rejected.

Fig. 4 shows that the rating system would reach equilibrium after the third year, except for rating KL. This condition is possible if there are no interventions from policy makers regarding the risk management in Islamic banks. Aside from using eigenvalue and eigenvector, this study als o employed various metrics to measure matrix distances to test the first order Markov assumption. There are two metrics used to test whether eigenvector from the transition matrix is constant, namely $\Delta \mathrm{M}_{\mathrm{AGL}}\left(\boldsymbol{\Lambda}(t), \boldsymbol{\Lambda}^{\prime}(t)\right)$ and $\Delta \mathrm{M}_{\mathrm{SVD}}$ $\left(\boldsymbol{\Lambda}(t), \Lambda^{\prime}(t)\right)$.

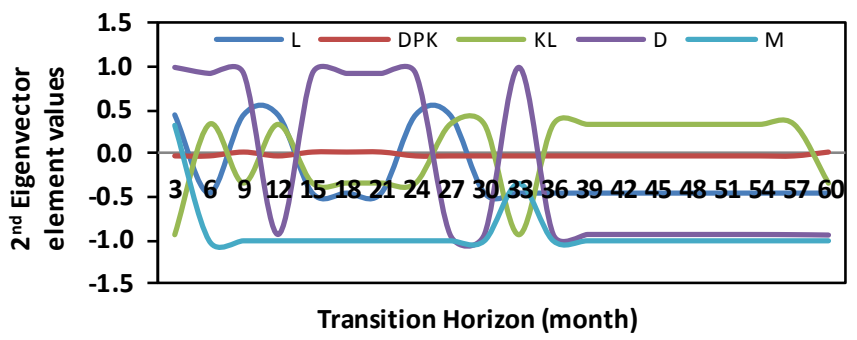

Fig. 4. Eigenvector analysis

Fig. 5 shows that both metrics are relatively varied all the time, even sometime exceeding 0.08. According to Arvanitis et al. [6], the time in-varying hypothes is of the eigenvector cannot be rejected if the value of the $\mathrm{M}_{\mathrm{AGL}}$ metric varied less than 0.08 all the time. Based on the analysis of both metrics, it can be surmised that the assumption of first order Markov chain process is not satisfied. This finding supports the result of hypothesis testing from Fig. 4.

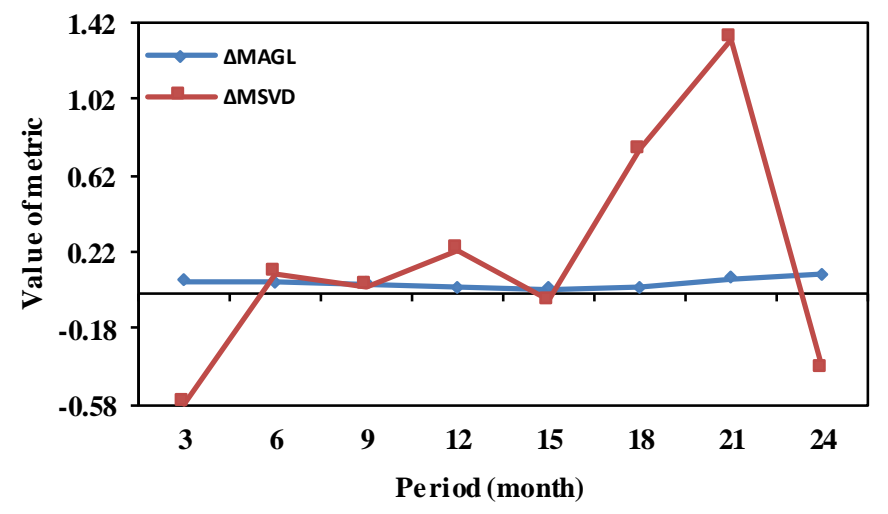

Fig. 5. Distance metric analysis

\subsubsection{Time dependent analysis: momentum and waiting time}

Table 4 shows that data confirm the presence of upgraded (downgraded) transitions in past which was followed by an upgrade (a downgrade) transition in present. Compared to the total transition (which are $17.184 \times 23=395.232$ transitions, included from (or to) NR), proportion of this momentum effect is relatively insignificant (which is $<$ $1.00 \%)$. Nevertheless, significance of this relation would be crucial once it is keyed to exposure value. No matter how small the data portion, analysis of momentum and waiting time effect is very urgent in the context of default risk mitigation.

Table 4 presents interesting rating transition behavior. In case of rating downgrade, the effect of momentum is clearly visible. The number of clients who previously experienced rating downgrade was greater than clients who experience downgrade at present time. Table 4 confirmed that most rating downgrade came from client with previous rating downgrade 
history, which is $57.15 \%$ for DPK-KL, $31.37 \%$ for KL-D, and $33.87 \%$ for D-M.

Table 4. Patterns of covariate and time to migrate

\begin{tabular}{|c|c|c|c|c|c|c|c|}
\hline \multicolumn{2}{|l|}{$\underline{\text { Rating }}$} & \multicolumn{3}{|c|}{$Z_{\mathrm{khj}}(\mathrm{t})$-Momentum } & \multicolumn{3}{|c|}{$Z_{\mathrm{h}}(\mathrm{t})$-W aiting Time } \\
\hline From $(\mathrm{h})$ & To $(j)$ & $\mathrm{N}_{\mathrm{kh}}(\mathrm{t}-1)$ & $\mathrm{N}_{\mathrm{hj}}(\mathrm{t})$ & $\mathrm{N}_{\mathrm{khj}}(\mathrm{t})$ & Mean & Max & Min \\
\hline \multicolumn{8}{|c|}{ Previous downgrade effect } \\
\hline DPK & KL & 169 & 21 & 12 & 1.524 & 3 & 1 \\
\hline $\mathrm{KL}$ & $\mathrm{D}$ & 1642 & 51 & 16 & 2.529 & 12 & 1 \\
\hline$\underline{\mathrm{D}}$ & $\mathrm{M}$ & 502 & 62 & 21 & 1.742 & 3 & 1 \\
\hline \multicolumn{8}{|c|}{ Previous upgrade effect } \\
\hline $\mathrm{D}$ & KL & 21 & 22 & 4 & 1.091 & 3 & 1 \\
\hline KL & DPK & 70 & 4 & 0 & 1.250 & 2 & 1 \\
\hline$\underline{\mathrm{DPK}}$ & $\mathrm{L}$ & 5 & 142 & 5 & 1.418 & 5 & 1 \\
\hline
\end{tabular}

On the other hand, clients with rating upgrade show the different behavior. Only few rating upgrade was followed by further rating upgrade. The effect of momentum toward rating upgrade is consistent only in DPK-L upgrade, even the probability is not substantial, only 5 out of 142 clients. This showed serious and consistent effort by Islamic banks to increase client's rating from KL to L. However, this effort was not too successful for client in rating $\mathrm{D}$, where the success of upgrade from D to KL was not followed by the success of upgrading rating from KL to DPK. This showed that in order to increase client's rating from $\mathrm{D}$ to $\mathrm{L}$ required at least two-month duration. This is similar to clients in rating M. Only $18.18 \%$ clients with rating $M$ were successful to be upgraded to rating KL for two months in a row. The difficulty of increasing client's rating in from rating $D$ and $M$ should be of concern by Islamic banks in running their financing portfolio.

Table 5. Effects of momentum and waiting time

\begin{tabular}{|c|c|c|c|c|c|c|c|c|c|c|}
\hline \multirow{2}{*}{$\begin{array}{l}\text { Rating } \\
\text { From (h) }\end{array}$} & \multirow{2}{*}{ To (j) } & \multicolumn{3}{|c|}{ Baseline Hazard Rate } & \multicolumn{2}{|c|}{$\mathrm{Z}_{\mathrm{h}}(\mathrm{t})$-Time $\mathrm{V}$} & \multirow{2}{*}{$\begin{array}{r}\text { Vaiting } \\
\text { prob } \\
\end{array}$} & \multicolumn{3}{|c|}{$\mathrm{Z}_{\mathrm{khj}}(\mathrm{t})$-Momentum } \\
\hline & & $\ln \alpha_{\mathrm{hj} 0}(\mathrm{t})$ & SE & prob & $\beta_{h}$ & $\mathrm{SE}$ & & $\beta_{h j}$ & SE & prob \\
\hline \multicolumn{11}{|c|}{ Downgrade effect } \\
\hline DPK & KL & 1.216 & 0.000 & 0.000 & -0.405 & 0.000 & 0.000 & 0.288 & 0.000 & 0.000 \\
\hline KL & $\mathrm{D}$ & 0.816 & 0.088 & 0.000 & -0.205 & 0.019 & 0.000 & 0.401 & 0.120 & 0.002 \\
\hline $\mathrm{D}$ & $\mathrm{M}$ & 1.387 & 0.127 & 0.000 & -0.467 & 0.055 & 0.000 & -0.006 & 0.103 & 0.954 \\
\hline \multicolumn{11}{|c|}{ Upgrade effect } \\
\hline D & KL & 1.490 & 0.193 & 0.000 & -0.497 & 0.161 & 0.006 & -0.414 & 0.174 & 0.028 \\
\hline KL & DPK & 1.792 & $\mathrm{n} . \mathrm{a}$ & n.a & -0.693 & n.a & $\mathrm{n} . \mathrm{a}$ & 0.000 & $\mathrm{n} . \mathrm{a}$ & n.a \\
\hline DPK & $\mathrm{L}$ & 1.511 & 0.024 & 0.000 & -0.457 & 0.014 & 0.000 & 0.045 & 0.069 & 0.519 \\
\hline
\end{tabular}

The reason for using present downgrade (upgrade) definition, specifically for the nearest rating, is because of the real existence of monotonistic behavior in transition matrix. Most rating transition will move to the nearest rating, before reaching the farther one. This is restrained because there is only small number of observations to estimate the model. This definition was also conducted by Lando and Skodeberg [17]. Table 5 shows null hypothesis that there is no downgrade (upgrade) momentum effect of previous rating, is rejected (except for case D-M and DPK-L). Except for D-M (downgrade) and D-KL (upgrade), which have negative signs, all other coefficients are positive. It shows that other than D$M$ and D-KL, the event of previous rating downgrade (upgrade) will lead to higher probability of present downg rade (upgrade). Table 5 also shows that to all cases of downgrade (upgrade), null hypothesis of the length of lag time does not affect/influence, is rejected. All beta coefficients, which have significant negative values, means that the longer lag time in the beginning rating, the smaller probability to experience downgrade (upgrade).

The above estimation result of transition matrices and behavioral testing of non-Markov was built from the data, which are aggregately gathered. Industrial effect as proven by Kavvathas [18] cannot be implemented to the sample of this research. Small number of samples makes the sub-samples, which represent each industry, insufficient to carry out the model estimation. In spite of that, by using generalization model as shown in eq. 11A (see Appendix), one will be able to test the effect of other various covariates, e.g.: business cycle effect [8] and many other macroeconomic factors.

In order to complement the study of waiting time effect to downgrade (upgrade), we would like to see when a rating will experience a downgrade (upgrade). By using Markov chain process, we redefine Markov process to examine downgrade (upgrade) probability for each waiting time. Table 6 shows that, in common, the longer waiting time, the smaller downgrade (upgrade) probability. This result is consistent with the previous result of modified Cox estimation model in Table 5. Anomaly of decreasing downgrade (upgrade) probability is only happened on the waiting time of two and three months. Especially for case L-DPK, downgrade probability has non-zero value, despite of more than six months waiting on rating L. It indicates two things. First, rating $\mathrm{L}$ is the most stable rating, even though it is important to be worried of since there is still a downgrade possibility after waiting for long time. Second, while for other ratings, including $\mathrm{M}$, tend to be unstable and can migrate within a short period.

Table 6. Pattern of probability to migrate

\begin{tabular}{|c|c|c|c|c|c|c|c|}
\hline \multicolumn{2}{|c|}{ Rating } & \multicolumn{6}{|c|}{ Time waiting (month) } \\
\hline \multicolumn{3}{|c|}{ From (i) To (j) 1} & 2 & 3 & 4 & 5 & 6 \\
\hline \multicolumn{8}{|c|}{ Downgrade } \\
\hline $\mathrm{L}$ & DPK & 0.013 & 0.030 & 0.031 & 0.045 & 0.045 & 0.018 \\
\hline DPK & KL & 0.394 & 0.424 & 0.182 & 0 & 0 & 0 \\
\hline KL & $\mathrm{D}$ & 0.240 & 0.109 & 0.186 & 0.093 & 0 & 0 \\
\hline $\mathrm{D}$ & $\mathrm{M}$ & 0.321 & 0.183 & 0.495 & 0 & 0 & 0 \\
\hline \multicolumn{8}{|c|}{ Upgrade } \\
\hline M & $\mathrm{D}$ & 0.528 & 0.056 & 0 & 0 & 0 & 0 \\
\hline $\mathrm{D}$ & KL & 0.875 & 0 & 0.125 & 0 & 0 & 0 \\
\hline KL & DPK & 0.600 & 0.400 & 0 & 0 & 0 & 0 \\
\hline DPK & $\mathrm{L}$ & 0.564 & 0.137 & 0.074 & 0.176 & 0.049 & 0 \\
\hline
\end{tabular}

\section{Conclusion}

Various metric testing conducted, i.e.: eigenvalue and eigenvector analysis, and also MAGL and MSVD metric, cannot distinctively accept or reject the assumption of transitional matrices homogeneity. It indicates that there is a possibility that transition probability matrices follow the assumption of non-homogenous time. This result is surely not gladden enough, recall that implication from using the above model with two assumptions lead to calculation of minimum 
required additional capital is different.

The semi-parametric linearity estimation result of modified Cox proportional hazard rate model shows that waiting time affects present downgrade (upgrade) rating in a significantly negative way. Previous downgrade (upgrade) momentum positively affected the waiting time, except for D-M (downgrade) and D-KL (upgrade) in negative way. Expansion of Markov chain process definition was used to study the length of waiting time required for each rating before experiencing downgrade (upgrade). The result shows that the longer the waiting time is, the smaller the downgrade (upgrade) probability will be. It shows consistency with the previous modified Cox model estimation result.

These various findings implied that Islamic banks should not only see client's current rating position to predict the rating transition in the future, but also examine other factors, such as previous rating transitions and the waiting time in the current rating. With various tables and graphics, which employed various measures of financing risk, Islamic banks can use it as basis for formulating an effective early warning system to improve existing bank's supervisory system. Various simulations on the proposed risk management policies could be conducted and the effect can be compared.

In practice, these findings imply that there are some clients who experienced a rating movement systematically. The momentum effect and waiting time effect in the current rating system should be included in Islamic banks risk management policies, especially, if Is lamic banks can gather the profile of these clients and their business. These issues are necessary, even though, in fact, there are over $99.00 \%$ of total clients in Indonesian Islamic banks following the memory-less property of the first order Markov chain process. This means that the client's rating migration in next period is purely random and only depends on their current rating. Implementing the mitigation policies that recognize the effects of momentum and waiting time for all of client may be biased and misleading.

The last issue is that the PLS contract is the form of financial partnership with a risk sharing concept (instead the risk transfer). Then the use of PLS contract is based on the condition that each partner (bank and client) has known each other. Naturally, client had a good track record in previous financing contract, such as murabahah or ijarah (usually for 2-3 years). So, the bank could trust the client and minimize the asymmetric information. In the PLS contract, the decrease in the performance of client's business is not only become a concern for the bank, but also the client. The client bears the risk as well as bank. Internally, the bank faces not only the investment risk and capital-loss risk, but als o the market risk, especially when the bank decides to divest from the business, by selling its share to the client or third parties. When we use the rating system, we must aware that some parameters of risk are frequently biased to the bank interest, where this concept is consistent with interest-based activities that rely on the risk transfer concept. So, in evaluating the risk of PLS contract, especially in use credit rating system, we should address the concept of risk sharing (instead risk transfer) and other characteristics of the PLS contract.

Finally, in this study, various factors determining the client's rating were excluded from the model. Using Markov approach, any client or client's business identification was eliminated, such as client's age, education level of client, duration of business running, industry sector, bank-client relationship, business's profitability, business cycle, and various macroeconomics indicators. Only client's rating was employed as variable in building financing risk model in Islamic banks in this study. Therefore, this study suggests for future research to employ various factors to build transition matrix-based client's supervisory system so that the resulted model can capture various effects of client, business and market, specific to each factor. This would provide better explanation on the various simulations based on metrics developed in this study.

\section{Acknowledgements}

The authors are grateful to Rizkiani Nugrahani Hermanto, Rizky Luxianto, and Muhammad Budi Prasetyo for the valuable discussion, data processing, and language checking. The authors are also obligated to Bambang Hermanto rahimahullahu. The remaining errors are our own responsibility.

\section{References}

1. O. O. Aalen, and S. Johansen, An empirical transition matrix for nonhomogeneous Markov chains based on censored observations: Scandinavian, J. Stat. 5 (1978) 141-150.

2. Akerlof, The Market for Lemons, Qualitative Uncertainty, and the Market Mechanisms, Quarterly J. Econ. 84 (1970) 488-500.

3. P. K. Andersen, L. S. Hansen, and N. Keiding, Non-and semiparametric estimation of transition probabilities from censored observation of a non-homogeneous Markov process, Scandin. J. Stat. 18 (1991) 153-167

4. P. K. Andersen, and O. Borgan, Counting Process Models for Life History Data: A Review, Scandin. J. Stat. 12 (1985) 97-158.

5. T. W. Anderson, and L. A. Goodman, Statistical inference about Markov chains, Annals Math. St at. 28 (1957) 89-1 10.

6. A. Arvanitis, J. Gregory, and J. P. Laurent, Building models for cre dit spreads, J. Deriv. 6 (1999) 27-43

7. M. Ayub, Understanding Islamic finance, Chicester, UK: John Wiley \& Sons Ltd., 2007.

8. A. Bangia, F. X. Diebold, A. Kronimus, C. Schagen, and T. Schuermann, Ratings migration and the business cycle, with application to credit portfolio stress testing, J.Bank. Financ. 26(2002)445-474.

9. A. Behren, and G. D. Pederson, An analysis of credit risk migration patterns of agricultural loans, Agricul. Financ. Rev. 67 (2007) 87-98.

10. J. Geweke, R. C. Marshall, and G. A. Zarkin, Mobility indices in continuous time Markov chains, Econometrica 54 (1986) 1407-1423.

11. Y. Jafry, and T. Schuermann, Measurement, estimation and comparison of credit migration matrices, J. Bank. Financ. 28 (2004) 2603-2639.

12. J. Janssen, and R. Manca, Semi-Markov risk models for finance, in surance and reliability, New York, USA: Springer Science+Busine ss Media, 2007.

13. R. A. Jarrow, D. Lando, and S. M. Turbull, A markov model for the tem structure of credit risk spreads, Rev. Financ. Stud. 10 (1997) 481-523.

14. J. D. Kalbfleisch, and R. L. Prentice, The statistical analysis offailure time data, New Jersey, USA: John Wiley\&Sons Inc., 2002.

15. E. L. Kaplan, and P. Meier, Nonparametric estimation from incomplete observations, J. Am. Stat. Assoc. 53 (1958) 457-481.

16. J. P. Klein, and M. L. Moeschberger, Survival analysis, techniques for censored and truncated data, New York, USA: Springer-Verlag, 2003.

17. D. Lando, and T. M. Skodeberg, Analyzing rating transitions and rating drift with continuous observations, J. Bank. Financ. 26(2002) 423-444.

18. D. Kavvathas, Estimating credit transition probabilities for co rpora te bonds, University of Chicago, USA: Working paper, 2000 (Retriev ed from: https://papers.ssm.com/sol3/papers.cfm?abstract_id=248421).

19. P. S. Mills, and J. R. Presley, Islamic finance: Theory and practice, Hampshire, UK: Palgrave Macmillan, 1999.

20. S. M. Ross, Introduction to probability models, San Diego, USA: Academic Press Inc., 1989.

21. A. F. Shorrocks, The Measurement of Mobility: Econometrica 46 (1978) 1013-1024. 
22. S. Trueck, and S. T. Rachev, Rating based modeling of credit risk: Theory and application of migration matrices, Burlington, MA: Academic Press Publication, 2009

23. H. Van Greuning, and Z. Iqbal, Risk analysis for Islamic banks, Washingt on, USA: The World Bank, 2008.

24. I. Wahyudi, Default risk analysis in micro, small and medium enterprises: Does debt overhang theory occur?, Asian Acad. Man. J. Acc. Financ. 10 (2014) 95-131.

25. I. Wahyudi, F. Rosmanita, M. B. Prasetyo, and N. I. S. Putri, Risk management for Islamic banks: Recent developments from Asia and the Middle East, Singapore: John Wiley \& Sons Pte.Ltd, 2015.

26. B. W. Taylor, Introduction to management science, Needham Heigh ts, MA: Simon \& Schuster Inc. , 1993.

\section{Appendix}

Continuous-time and Homogeneous Markov Model

\section{A1. Markov process}

Suppose process $[X(t), t \geq 0]$ as a random variable following stochastic process with continuous time - which shows a single firm in the system $S$ on state (rating) $i$ at time $t$. While $[X(t), t \geq 0]$ is continuous-time Markov process, if for all $s, t \geq 0$ and integer value $i, j, x(u)$, and also $0 \leq u<s$ considered as follows:

$$
\begin{gathered}
P[X(s+t)=j \mid X(s)=i, X(u)=x(u), 0 \leq u<s] \\
=P[X(s+t)=j \mid X(s)=i]
\end{gathered}
$$

If $P[X(s+t)=j \mid X(s)=i]$ is independent to $s$, then the continuous-time Markov chain process will have stationary or homogeneous transitional probability.

Suppose $T_{i}$ shows the length of time a firm stays on a state (rating) $i$ before migrating to different state $j$, for all s, $t \geq 0$, then $P\left[T_{i}>s+t \mid T_{i}>s\right]=P\left[T_{i}>t\right]$. Then, $T_{i}$ can be considered memory-less and should be exponentially distributed (for $e^{-\lambda(s+t)}=e^{-\lambda s} \cdot e^{-\lambda t}$, where $\lambda$ shows the average of migration rate). These Markov properties can be rewritten as follows:

$P\left[T_{i}>s+t, T_{i}>s\right] / P\left(T_{i}>s\right)=P\left(T_{i}>t\right)$ or $P\left[P\left(T_{i}>\right.\right.$ $s+t)]=P\left(T_{i}>s\right) \cdot P\left(T_{i}>t\right)$

Using Chapman-Kolgomorov differential equation, for various pair of state $i$ and $j$, then: $\lambda_{i j}=\lambda_{i} P_{i j}$. Where $\lambda_{i j}$ is a transitional rate from state $\mathrm{i}$ to $\mathrm{j}, \lambda_{i}$ is the rate at which the firms in state $i$ made a transition, and $P_{i j}$ means the transition probability from state $i$ to state $j . \lambda_{i j}$ is also said as instantaneous transition rate for: $\lambda_{i}=\sum_{j} \lambda_{i} . P_{i j}=\sum_{j} \lambda_{i j}$ and $P_{i j}=\lambda_{i j} / \lambda_{i}=\lambda_{i j} / \sum_{j} \lambda_{i j}$. In conclusion, $\lambda_{i j}$ may be defined as migration intensity. By using equation $1 \mathrm{~A}, P_{i j}(t)$ can be rewritten as follows:

$$
P_{i j}(t)=P[X(s+t)=j \mid X(s)=i]
$$

For all $s \geq 0, t \geq 0$, Chapman-Kolmogorov equation can be defined as:

$$
P_{i j}(s+t)=\sum_{k=0}^{\infty} P_{i k}(s) \cdot P_{k j}(t)
$$

By using lemma, that for time limit $\mathrm{s}$ approximates to zero (0), we get:

$$
\begin{gathered}
\lim _{s \rightarrow 0} \frac{1-P_{i j}(s)}{S}=\lambda_{i} \\
\lim _{s \rightarrow 0} \frac{P_{i j}(s)}{s}=\lambda_{i j}
\end{gathered}
$$

By deducting both sides of equation $3 \mathrm{~A}$ with $P_{i j}(t)$, we obtain:

$$
\begin{aligned}
P_{i j}(s+t) & -P_{i j}(t)=\left[\sum_{k=0}^{\infty} P_{i k}(s) \cdot P_{k j}(t)\right]-P_{i j}(t) \\
& =\left[\sum_{k \neq i}^{\infty} P_{i k}(s) \cdot P_{k j}(t)\right]+P_{i i}(s) \cdot P_{i j}(t) \\
& -P_{i j}(t)
\end{aligned}
$$

$$
=\left[\sum_{k \neq i}^{\infty} P_{i k}(s) \cdot P_{k j}(t)\right]-\left[-P_{i i}(s) \cdot P_{i j}(t)\right]
$$

By considering time limit $s \rightarrow 0$ both sides of equation 4A, $P_{i j}(s+t)=P_{i j}(t+s)$, and by replacing each other's limit and sum, will be obtained result as follows:

$$
\begin{gathered}
\lim _{s \rightarrow 0} \frac{P_{i j}(t+s)-P_{i j}(t)}{s} \\
=\lim _{s \rightarrow 0}\left\{\left[\sum_{k \neq i}^{\infty} P_{i k}(s) \cdot P_{k j}(t)\right]\right. \\
\left.-\left[1-P_{i i}(s) \cdot P_{i j}(t)\right]\right\} \\
P_{i j}^{\prime}(t)=\left[\sum_{k \neq i} \lambda_{i j} \cdot P_{i j}(t)\right]-\lambda_{i} \cdot P_{i j}(t)
\end{gathered}
$$

Equation $5 \mathrm{~A}$ is called as Kolgomorov's backward equation. Lets for each pair of state $i$ and $j$, defined that:

$$
r_{i j}=\left\{\begin{array}{l}
\lambda_{i j} \text { if } i \neq j \\
-\lambda_{i} \text { if } i=j
\end{array}\right.
$$

Hence, the equation $5 \mathrm{~A}$ can be rewritten as follows:

$$
P_{i j}^{\prime}(t)=\sum_{k} r_{i k} \cdot P_{k j}(t) \text { or } \boldsymbol{P}^{\prime}(t)=\boldsymbol{R} \cdot \boldsymbol{P}(t)
$$

Where: $P^{\prime}(t)$ is matrix $n \times n$ transition probability of the next 1 period,

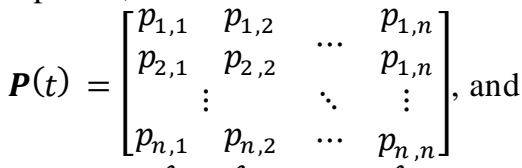

$$
\begin{aligned}
& \boldsymbol{R}(t)=\left[\begin{array}{ccccc}
-\lambda_{1} & \lambda_{1,2} & & \lambda_{1, n} \\
\lambda_{2,1} & -\lambda_{2} & & \lambda_{1, n} \\
& \vdots & & \ddots & \vdots \\
\lambda_{n, 1} & \lambda_{n, 2} & \cdots & -\lambda_{n}
\end{array}\right] .
\end{aligned}
$$

By using scalar equation differential solution method (which if $\left.f^{\prime}(t)=c f(t) \rightarrow f(t)=f(0) \cdot e^{c t}\right)$, the solution of the above matrices differential equation is as follows:

$$
\boldsymbol{P}(t)=\boldsymbol{P}(0) . \boldsymbol{e}^{\boldsymbol{R} t} \text { or } \boldsymbol{P}(t)=\boldsymbol{e}^{\boldsymbol{R} t}
$$

\section{A2. Estimator life table (ELT)}

ELT was developed by Kaplan and Meier [15] using life table, where summary of survival data is grouped into few intervals, $I_{1}, \ldots, I_{k}$, and thus: $I_{j}=\left(b_{0}+\cdots+b_{j-1}, b_{0}+\cdots+b_{j}\right)$ is width $b_{j}$ with $b_{0}=0$. Life table represents number of default and censored survival time which felt into each interval. For example, $m_{j}$ is a censored time and $d_{j}$ is default time which falls into interval $I_{j}$, and $n_{j}=\sum_{l \geq j}\left(d_{l}+m_{l}\right)$ is the number of risky firms in the beginning of interval $j$. ELT default probability in $I_{j}$ with survival requirement until $I_{j}$ is: $\hat{q}_{j}=1$ if $n_{j}=0$ and $\hat{q}_{j}=\frac{d_{j}}{n_{j}-\left(m_{j} / 2\right)}$ if $n_{j} \neq 0$. Where factor $\left(m_{j} / 2\right)$ is used to capture the fact that not all firms $n_{j}$ are at risk for all $I_{j}$. ELT for survivor function, $\hat{F}$, at the end of $I_{j}$ is: $\hat{F}\left(b_{1}+\cdots+\right.$ $\left.b_{j}\right)=\prod_{l=1}^{j}\left(1-\hat{q}_{l}\right)$.

ELT is used for conditions in which actual default and censored time were unavailable, while only $d_{j}$ dan $m_{j}$ available for interval $j$. Lets for example, there is an actual (continuous) default time and $t_{j 1}, \ldots, t_{j r_{j}}$ is observed time in $I_{j}$ where $m_{j}$ is sum of censored, $d_{j}$ is sum of default, $r_{j}=d_{j}+m_{j}$ and $j=$ $1, \ldots, k$. Lets Hazard function, $\lambda(\mathrm{t})$, is taken so that value of $\lambda$ within interval $I_{j}$ to be constant, then MLE of $\lambda_{\mathrm{j}}$ is $\hat{\lambda}_{j}=\frac{d_{j}}{s_{j}}$ where $S_{j}=\sum_{l-1}^{r_{j}}\left(t_{j l}-\sum_{i=0}^{j-1} b_{i}\right)+n_{j+1} b_{j}$ is the total observed survival time within interval $I_{j}$. Hence, the survivor function of ELT for $t \in I_{j}$ can be defined as $\hat{F}(t)=\exp \left[-\hat{\lambda}_{j}(t-\right.$ 
$\left.\left.\sum_{l=0}^{j-1} b_{l}\right)-\sum_{i=1}^{j-1} \hat{\lambda}_{i} b_{i}\right]$. This definition enable the use of rating withdrawal as a right censoring observation and produce its own instantaneous hazard rate, which is $\lambda(t)=$ $\sum_{j=1, j \neq i}^{J} \lambda_{i j}(t)$.

Survival probability is defined as not-failing intensity cumulative within the firm's lifetime which calculated as exponential of negative value from hazard rate, which for $\Delta t / t$ is integer and $\mathrm{A}$ is survive events, and thus $P(A)=$ $\exp \left\{-\left(\sum_{j=1, j \neq i}^{J} \lambda_{i j}\right) t\right\}$. By considering both right and left censor scheme, duration contribution 1 for failure to state $j$ from state $i$ at the time $t$ is $\lambda_{i j} \exp \left[-\int_{0}^{t_{l}}\left(\sum_{k=l, k \neq i}^{J} \lambda_{i k}\right) d u\right]$. In censored case, the default is considered as not yet happened until we dispose cause-specific hazard rate. Let $N_{j}$ is the number of default events to state $j$ and $N_{c}$ is the number of censored observation, with original rating (matrix row) 1 and $N$ is the number of total observation either censored or uncensored, then:

$L_{l}=\left[\prod_{j=1, j \neq l}^{J}\left\{\prod_{i=1}^{N_{j}} \lambda_{j} \exp \left(-\int_{0}^{t_{i}} \sum_{j=1, j \neq i}^{J} \lambda_{j} . d u\right)\right\}\right] \prod_{i=1}^{N_{c}} \exp \left(-\int_{0}^{t_{i}} \sum_{j=1, j \neq i}^{J} \lambda_{j} . d u\right)$ By taking the first differential from the above log likelihood, we obtain:

$$
\lambda_{j}=\frac{N_{j}}{\sum_{i=1}^{N} t_{i}} \text { or } \lambda_{i j}=\frac{N_{i j}}{\sum_{i=1}^{N} t_{i}}=\left[\frac{N_{i j}}{N_{i}}\right] /\left[\frac{\sum_{i=1}^{N} t_{i}}{N_{i}}\right]
$$

In other notation, it can be stated as: $\lambda_{i j}=\frac{N_{i j(T)}}{\int_{0}^{T} Y_{i}(s) d s}$ where $\lambda_{i j}$ is the instantaneous hazard rate from state $i$ to state $j, N_{i j}(T)$ is sum of total transition from state $i$ to state $j$ within period $[0, T]$ and $Y_{i}(s)$ means sum of firms on rating $i$ at time $s$.

\section{A3. Time Dependence Effect}

Suppose a random process, $X_{\mathrm{i}}$, follows the Markov chain process if $P\left(X_{n}=x_{n} \mid X_{0}=x_{0}, X_{1}=x_{1}, \ldots, X_{n-1}=x_{n-1}\right)=P\left(X_{n}=x_{n} \mid X_{n}\right.$. $\left.1=x_{n-1}\right)$ is valid for $\mathrm{i}=0,1, \ldots, \mathrm{n}$. The probability of future event $\left(X_{n+1}\right)$ is only influenced by the present event $\left(X_{n}\right)$ and independent from past events. Ross [20] defined this behavior as the memory-less property. Bangia et al. [8] used this property to test the assumption of first order Markov chain process for transition matrices. Similar with Bangia et al [8], Lando and Skodeberg [17] defined time dependence (covariate) as when present rating upgrade (downgrade) is influenced by upgrade (downgrade) in before. Time covariate obviously violates the memory-less property.

Bangia et al. [8] used conditional and unconditional transition matrices to analyze the presence of one period time dependence within rating migration. Behren and Pederson [9] defined that downgraded (upgraded) momentum pattern will exist if only the probability of such downgraded (upgraded) is higher for previously downgraded (upgraded) compared to previously upgraded (downgraded). Testing for time-path dependence needs three matrices which is conditionally arranged to the previous migration direction, which are downgrade, no change, or upgrade. Following Anderson and Goodman [5], they tested null hypothesis, $H_{0}: \pi^{d}=\pi^{n c}=$ $\pi^{u}$, using a chi square test with statistical test: $\chi^{2}=$ $\sum_{i} \sum_{c, j}\left(\frac{n_{i}^{c}\left(P_{i j}^{c}-P_{i j}\right)^{2}}{P_{i j}}\right)$ and degree of freedom $m(m-1)(c-$ 1 ), where $m$ means the sum of rating class.

Lando and Skodeberg [17] used Cox model and AalenJohansen methodology generalization to test time dependent covariate. Under independent censoring, counting process for each client can be defined as follows:

$$
N_{h j i}(t)=\int_{0}^{t} \alpha_{h j i}(u) Y_{h i}(u) d u+M_{h j i}(t)
$$

Where $N_{h j i}(t)$ is number of observed transition from rating $\mathrm{h}$ to $\mathrm{j}$ by client $\mathrm{i}$ at time $\mathrm{t}, Y_{h i}(u)$ is the process indicator to experience transition, which will be valued as 1 when client $i$ is on rating $\mathrm{h}$ and 0 if others, and $M_{h j i}(t)$ is a martingale from a filtrate of $N_{h j i}(t)$ and $Y_{h i}(u)$.

Furthermore, Andersen et al. [3] and Klein and Moeschberger [16] defined that for each i with timedependent covariate vector $Z_{h j i}(t)$, transition intensity $h \rightarrow j$ defined as a proportionate intensity model:

$$
\lambda_{h j i}(t)=Y_{h i}(t) \alpha_{h j i}\left(t, Z_{h j i}(t)\right)
$$

Where: $\quad \alpha_{h j i}\left(t, Z_{h j i}(t)\right)=\alpha_{h j 0}(t) \exp \left(\beta_{h j} Z_{h j i}(t)\right)$, and $Z_{h j i}(t)$ is a vector of type specific covariate [4] which will be valued as 1 if client $\mathrm{i}$ were upgraded to present rating class (previously upgraded) and 0 in others. Based from observation $N_{h j i}(t), Y_{h i}(t)$ and $Z_{h j i}(t)$, the true parameter vector $\beta_{0}$ can be estimated with value $\hat{\beta}$ by maximizing Cox partial likelihood model to $\beta_{h j}$ :

$$
L\left(\beta_{h j}\right)=\prod_{t} \prod_{h j i} \frac{\exp \left(\beta_{h j} Z_{h j i}(t)\right)^{\Delta N_{h j i}(t)}}{S_{h j}^{0}\left(\beta_{h j}, t\right)}
$$

Where $S_{h j}^{0}\left(\beta_{h j}, t\right)=\sum_{i=1}^{n} Y_{h i}(t) \exp \left(\beta_{h j} Z_{h j i}(t)\right)$. Using the (partial) likelihood test, Lando and Skodeberg [17] tested the null hypothesis of no rating drift, with statisticaltest:

$$
L R=-2 \ln \left(\frac{L\left(\bar{\beta}_{h j}\right)}{L\left(\hat{\beta}_{h j}\right)}\right)=2\left(L\left(\hat{\beta}_{h j}\right)-\ln L\left(\bar{\beta}_{h j}\right)\right)
$$

In which LR follows (asymptotic) chi-square distribution with one degree of freedom.

In this research, to test the effect of previous downgrade (upgrade) momentum and waiting time in beginning rating $h$ by ignoring all client $\mathrm{i}$ with censored $\mathrm{Y}_{\mathrm{hi}}(\mathrm{t})$, Eq. 9A can be rewritten as follows:

$$
\lambda_{h j i}(t)=\alpha_{h j 0}(t) \exp \left(\beta_{h j} Z_{h j i}(t)+\beta_{h} Z_{h i}(t)\right)
$$

Where $\lambda_{h j i}(t)$ defined for each client $i, Z_{h j i}(t)$ is covariate, which will be valued as 1 if previous downgrade (upgrade) followed by present downgrade (upgrade), and $Z_{h i}(t)$ is waiting time covariate in beginning rating $h$ before experiencing present downgrade (upgrade).

This model was developed from Cox proportional hazard rate model [14]. By logarithm both sides on eq. 10A, we can obtain:

$$
\ln \lambda_{h j i}(t)=\ln \alpha_{h j 0}(t)+\beta_{h j} Z_{h j i}(t)+\beta_{h} Z_{h i}(t)
$$

